\title{
CONSERVAÇÃO DE ÁGUA E SOLO A MONTANTE DA ÁREA DE CAPTAÇÃO DE ÁGUA DA SANEAGO EM IPORÁ-GO
}

\author{
Flávio Alves de Sousa ${ }^{(a)}$, Lilia Silva ${ }^{(b)}$, Luthiane Silva Alves ${ }^{(c)}$ \\ (a) Professor do curso de geografia da Universidade Estadual de Goiás (UEG) -flavio.alves@ueg.br \\ (b) Bolsista PIBIC/UEG - liliasilva@ hotmail.com \\ (c) Bolsista PIVIC/UEG - luthisilva@ hotmail.com

\section{EIXO: BACIAS HIDROGRÁFICAS E RECURSOS HÍDRICOS: ANÁLISE, PLANEJAMENTO E GESTÃO}

\begin{abstract}
Resumo
O presente trabalho teve como objetivo avaliar as condições de conservação ambiental na alta bacia hidrográfica do Ribeirão Santo Antônio, pois nesta faixa da bacia está a captação de água, que é tratada e distribuida para o consumo da população iporaense.O estudo avaliou e mapeou as condições de declividade do relevo para entender a dinâmica do fluxo superficial da água das chuvas; coletou e analisou amostras de solos das áreas de relevo plano (Latossolos); mapeou as classes de solos presentes na bacia e mapeou o uso e ocupação das terras; também foram realizados testes de condutividade hidráulica dos Latossolos para entender como estes auxiliam na recarga do lençol freático. Apesar da conservação ambiental na bacia não ser a ideal não chega a ser um problema significativo para a conservação da água e dos solos. Com planejamento e manejos simples é possível conseguir uma boa qualidade ambiental na área estudada.
\end{abstract}

Palavras-chave: Planejamento, conservação, análise.

\section{Introdução}

Conforme Sousa (2006), a bacia hidrográfica do Ribeirão Santo Antônio ocupa aproximadamente 1/3 da área do município de Iporá, e se estende por mais dois municípios vizinhos. Na sua parte mais a montante, está localizada a estação de captação de água da SANEAGO. As características físicas da bacia hidrográfica, bem como o tipo de uso dos solos que a ela é destinado, influenciam significativamente na qualidade de suas águas, podendo onerar o sistema de captação e tratamento.

Ainda conforme Sousa (2006), o estudo sobre as potencialidades físicas da bacia, pode contribuir positivamente para uma melhor exploração da mesma, de forma a melhorar a produtividade, a preservação de seus recursos naturais e a vida da população envolvida, bem como subsidiar projetos econômicos, de uso e manejo, além de recuperação das áreas degradadas.

Em uma bacia hidrográfica, a inter-relação entre os fenômenos que ali se manifestam resultam num intercâmbio de energia e matéria, que a caracteriza como um sistema aberto, e da combinação entre os elementos do sistema é que surgem as características de cada bacia hidrográfica.

Hall \& Fagan (1956), apud Chorley (1971), definiram um sistema como "um conjunto de objetos com 
OS DESAFIOS DA GEOGRAFIA FÍSICA NA FRONTEIRA DO CONHECIMENTO

Instituto de Geociências - Unicamp

Campinas - SP

28 de Junho à 02 de Julho de 2017

relações estreitas entre si e entre seus atributos", atributos estes representados pelos elementos que compõem o sistema. As bacias de drenagem representam um exemplo importante de sistema aberto, graças ao grande número de elementos que nela interagem. As bacias hidrográficas são consideradas ainda como um sistema aberto, onde a entrada está representada pela chuva e radiação solar e as saídas pelas descargas dos rios e a evaporação (Neto \& Batista, 1995).

Como um sistema aberto, a bacia hidrográfica sofre constantes alterações em seus elementos, principalmente após o advento da exploração econômica de suas terras, seja em nível urbano ou rural, o que resulta em combinações diversas dos elementos e alterações no seu fluxo de energia e matéria, exigindo assim, uma melhor avaliação de seu uso, o que só é possível através de um manejo adequado da mesma.

A utilização da bacia hidrográfica como unidade de estudo e gestão ambiental, para o gerenciamento das diferentes formas de ocupação e uso das diversas potencialidades ambientais (recursos minerais, florestais, agropecuários, hídricos, pesqueiro, energético entre outros) têm como objetivo planejar, coordenar, executar e manejar as melhores formas de apropriação e exploração desses recursos ambientais, proporcionando o desenvolvimento socioeconômico das suas respectivas populações, bem como a sustentabilidade dos recursos ambientais, diminuindo ou evitando a degradação da qualidade de vida.

O termo manejo de bacias hidrográficas, segundo Valente (1976), engloba todos os tratos que venham a sofrer os recursos naturais da bacia hidrográfica, visando assegurar o máximo suprimento de água dentro de princípios técnicos e econômicos.

O manejo de bacias hidrográficas deve ser entendido como o conjunto de procedimentos resultantes de trabalho integrado, multi e interdisciplinar, que deve ser conduzido para identificar e indicar opções de soluções aos problemas que alteram os sistemas ambientais, que na maior parte dos casos conduzem à deterioração de seus recursos naturais e dos sistemas produtivos. SILVA \& $\operatorname{BARROS}(2003$, p. 23).

As alterações ambientais que ocorrem nas bacias hidrográficas, em função da acelerada ocupação humana, variam de acordo com a potencialidade econômica de cada lugar, potencialidade esta que depende de fatores como clima, características das encostas, topografia, geologia, grau de intemperismo e formação dos solos. Desta forma, a análise física da bacia hidrográfica, permite a realização de um zoneamento da mesma, de acordo com o grau de fragilidade de seus compartimentos. Tal fragilidade, segundo Ross (1990), está representada por indicadores como a intensidade de rugosidade topográfica, que associada à declividade, solos, geologia e pluviosidade pode demonstrar suscetibilidades erosivas e tendências a movimentos de massa. Associem-se a isso informações sobre cobertura vegetal e uso da terra para se obter importantes informações fisiológicas sobre uma dada 
bacia hidrográfica.

No estudo das características físicas da bacia hidrográfica é muito importante relacionar o índice de precipitação com as características topográficas, principalmente as classes de declividades das vertentes, que influenciam no equilíbrio das encostas, sendo um dos fatores da erosão potencial e dos movimentos de massa. (GUERRA E CUNHA, 2003).

A dinâmica das vertentes é função dos fatores climáticos, topográficos e de uso da terra. Bigarella (1978), lembra que desmoronamentos acentuados ocorrem em vertentes muito íngremes e de solos pouco espessos e saturados, mesmo sob floresta, quando é registrada grande intensidade de precipitação.

O conhecimento do substrato geológico também é de fundamental importância no estudo do potencial físico de uma bacia hidrográfica, "e adquire maior importância quando associado à topografia" (Guerra \& Cunha, 2003).

$\mathrm{Na}$ ação humana sobre a natureza, a variável do ecossistema mais vulnerável é a cobertura vegetal que é a base do seu equilíbrio. Sua retirada provoca sequelas em todas as outras variáveis do meio, como solos, relevo e ciclo da água. Para Tricart (1977), a retirada da cobertura vegetal repercute sobre a energia da radiação que alcança o solo e, por sua vez, na sua temperatura, com efeitos sobre a fauna e flora, a mineralização do húmus, a nitrificação, enfim, sua fertilidade, isso sem contar a redução na capacidade de resistência à erosão pluvial.

Não se pode esquecer a cobertura vegetal, que defende o terreno contra a erosão através da proteção contra o impacto direto das gotas de chuva; dispersão e quebra da energia das águas de escoamento superficial; aumento da infiltração pela produção de poros no solo por ação das raízes; aumento da retenção de água pela estruturação do solo por efeito da produção e incorporação de matéria orgânica (Bertoni \& Lombardi Neto, 1985).

Há ainda que se considerar, que a caracterização física de determinada área, deve sempre estar vinculada a uma proposta de planejamento numa visão de sustentabilidade quando se pensa em desenvolvimento econômico e ambiental, pois os estudos ambientais devem procurar compatibilizar o desenvolvimento da economia humana com as restrições impostas pela natureza, o que favoreceria a redução da degradação ambiental que advém dos processos de desenvolvimento e ocupação do espaço pelas atividades humanas. (SOUSA, 2006)

\section{Procedimentos metodológicos}

O desenvolvimento do projeto contou com uma fase teórica, quando foram analisadas obras 


\section{OS DESAFIOS DA GEOGRAFIA FÍSICA NA FRONTEIRA DO CONHECIMENTO Instituto de Geociências - Unicamp$$
\text { Campinas - SP }
$$ \\ 28 de Junho à 02 de Julho de 2017}

bibliográficas que auxiliaram na compreensão dos fenômenos físicos da paisagem e na elaboração de procedimentos práticos para identificar, medir, e analisar os fenômenos naturais.

Foram baixadas informações cartográficas para compor a confecção dos mapas temáticos. As informações foram: dados altimétricos, baixados do Topodata do INPE (Instituto Nacional de Pesquisas Espaciais); dados geológicos baixados do Geobank no site do CPRM; dados hidrográficos e limites de município extraídos do site do SIEG-GO. Utilizou-se também o Google Earth como suporte para mapeamento do uso da terra, delimitação da área da bacia e sobreposição de dados de geologia (extraídos do Geobank) e posicionados sobre a área de interesse na bacia.

Todos os dados citados foram trabalhados no software Quantum GIS. Dados de uso das terras foram gerados no Google Earth e exportados no formato $K M L$ para o Quantum Gis.

Os mapas gerados foram: o de localização da bacia, declividades, solos, uso e ocupação das terras.

A identificação e mapeamento das classes de solos foram realizados com auxílio das feições geológicas da bacia, do mapa de declividades, da imagem de satélite e através de incursões em campo, onde se aproveitou para coletar amostras de Latossolos e realizar testes de condutividade hidráulica dos mesmos.

As amostras de solos coletadas (num total de 16) em vários pontos da bacia foram levadas para o laboratório, onde se realizaram análises de textura, pois estas análises ajudam a entender a dinâmica da condutividade hidráulica de cada classe de solos. Para as análises texturais foi utilizado o método do densímetro de Bouyoucos (1927) descrito por Gee \& Bauderi (1986).

Para os testes de condutividade hidráulica dos solos foi utilizado o Infiltrômetro Mini-Disck, que consiste em aparelho de tamanho reduzido, de fácil manejo e de alta precisão e com pouquíssima utilização de água. Para cada ponto de coleta de solo foram realizados três testes de condutividade hidráulica, e os resultados médios são apresentados neste relatório.

\section{Resultados e discussões}

A bacia do Ribeirão Santo Antônio pertence à bacia hidrográfica do Araguaia e localiza-se entre os paralelos $16^{\circ} 19^{\prime} 45^{\prime \prime}$ e $16^{\circ} 42^{\prime} 05^{\prime \prime}$ de latitude sul e os meridianos $51^{\circ} 04^{\prime} 30^{\prime \prime}$ e $51^{\circ} 23^{\prime} 27^{\prime \prime}$ de longitude oeste. A bacia está representada na figura a seguir. 


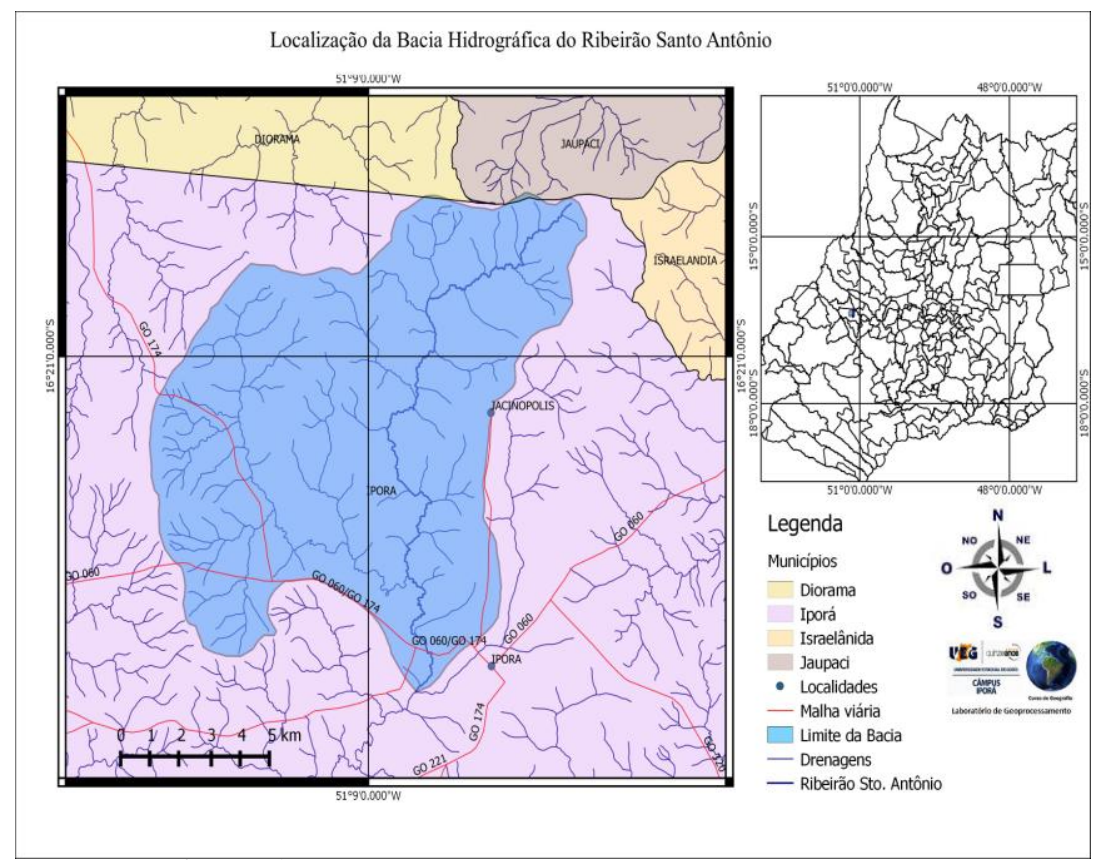

Figura 1. Alta Bacia Hidrográfica do Ribeirão Santo Antônio.

A bacia em questão apresenta litologia predominantemente granítica de idade Paleozóica em quase sua totalidade, aparecendo em alguns pontos, coberturas sedimentares das formações Furnas e Ponta Grosa de idade Siluro/Devoniana, bem como coberturas detrítico-lateríticas de idade Cenozóica. Apresenta ainda rochas alcalinas (Gabros e Piroxenitos) de idade Cenozóica.

A drenagem apresenta padrão dendrítico e a cobertura vegetal nativa (mata ciliar) ainda é razoavelmente preservada em cerca de $40 \%$ da extensão dos mananciais, embora não atinjam em muitos pontos as larguras determinadas pelo novo código florestal.

O relevo varia de plano a suave ondulado com declividade predominantemente plana, entre 0 e $6 \%$. As áreas de divisores apresentam declividades mais acentuadas, entre de 12 a $>20 \%$, sendo que a oeste da bacia os divisores são sustentados por rochas graníticas e a norte e nordeste por rochas alcalinas (Gabros e Piroxenitos). O mapa a seguir mostra as declividades predominantes na bacia. 


\section{OS DESAFIOS DA GEOGRAFIA FÍSICA NA FRONTEIRA DO CONHECIMENTO \\ Instituto de Geociências - Unicamp \\ Campinas - SP \\ 28 de Junho à 02 de Julho de 2017}

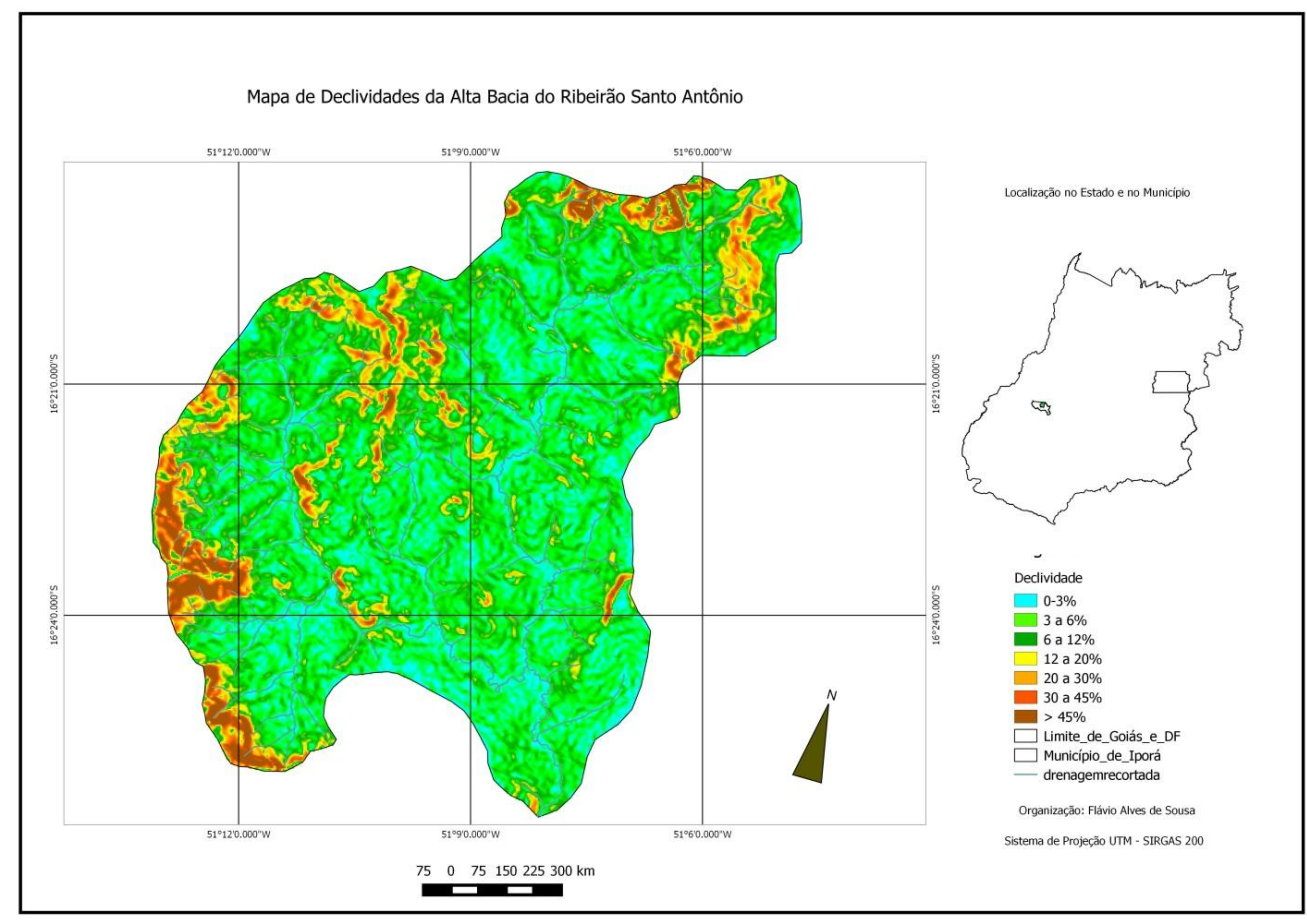

Figura 2. Mapa de Declividades

Os Latossolos analisados apresentam texturas predominantemente argilosas a muito argilosa (75\%) e Franco argilo/arenosa em 25\% das amostras, como é possível ver na pirâmide textural e no quadro 1.

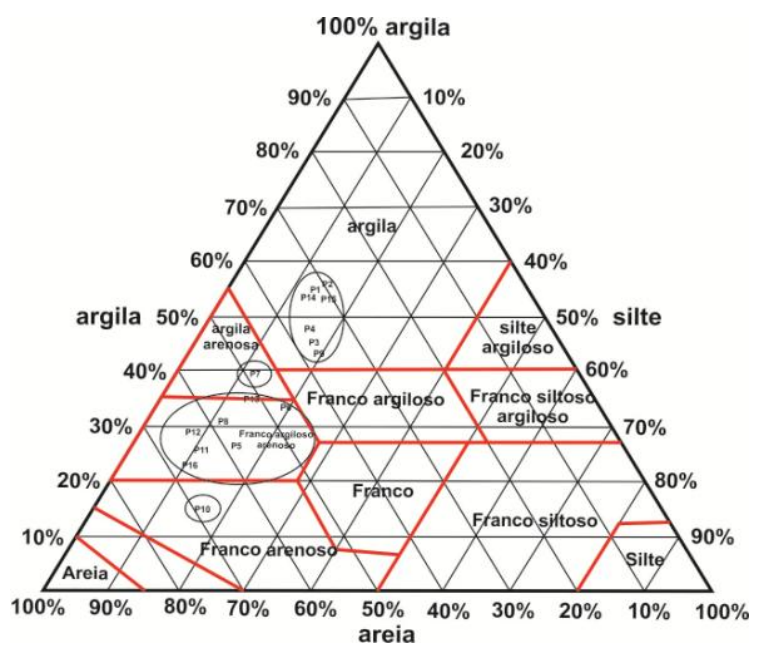

Figura 3. Pirâmide textural dos Latossolos.

Quadro I. Frações texturais dos Latossolos da Alta bacia do Ribeirão Santo Antônio

\begin{tabular}{|c|c|c|c|c|c|}
\hline Amostra & Classe & $\begin{array}{c}\text { Argila } \\
(\boldsymbol{\%})\end{array}$ & $\begin{array}{c}\text { Silte } \\
(\boldsymbol{\%})\end{array}$ & $\begin{array}{c}\text { Areia } \\
(\%)\end{array}$ & Total \\
\hline 1 & Latossolo Vermelho Muito-escuro & 55 & 13 & 32 & 100 \\
\hline 2 & Latossolo Vermelho Muito-escuro & 56 & 14 & 30 & 100 \\
\hline 3 & Argissolo Vermelho-Escuro & 45 & 18 & 37 & 100 \\
\hline 4 & Latossolo Vermelho-Amarelo & 48 & 16 & 36 & 100 \\
\hline 5 & Latossolo Vermelho-Escuro & 25 & 15 & 60 & 100 \\
\hline 6 & Latossolo Vermelho-Escuro & 35 & 20 & 45 & 100 \\
\hline
\end{tabular}


VII Simpósio Brasileiro de Geografia Fisica Aplicada

I Congresso Nacional de Geografia Física

\section{OS DESAFIOS DA GEOGRAFIA FÍSICA NA FRONTEIRA DO CONHECIMENTO \\ Instituto de Geociências - Unicamp \\ Campinas - SP \\ 28 de Junho à 02 de Julho de 2017}

\begin{tabular}{|c|c|c|c|c|c|}
\hline 7 & Latossolo Vermelho-Amarelo & 41 & 12 & 47 & 100 \\
\hline 8 & Latossolo Vermelho-Amarelo & 32 & 12 & 56 & 100 \\
\hline 9 & Latossolo Bruno amarelado & 43 & 20 & 37 & 100 \\
\hline 10 & Latossolo Bruno avermelhado & 16 & 17 & 67 & 100 \\
\hline 11 & Latossolo Bruno avermelhado & 27 & 11 & 62 & 100 \\
\hline 12 & Latossolo Bruno escuro & 30 & 10 & 60 & 100 \\
\hline 13 & Latossolo Bruno avermelhado & 36 & 13 & 51 & 100 \\
\hline 14 & Latossolo Bruno escuro & 55 & 13 & 32 & 100 \\
\hline 15 & Latossolo Bruno escuro & 54 & 14 & 32 & 100 \\
\hline 16 & Latossolo Bruno amarelado & 25 & 11 & 64 & 100 \\
\hline
\end{tabular}

Os Latossolos correspondem à maior parte da bacia, o que caracteriza uma área de recarga do lençol freático da ordem de 60,8\%. Todavia as áreas planas onde se desenvolvem os Latossolos são descontínuas e geralmente estes solos apresentam uma compactação superficial, que dificulta a infiltração de água.

Apesar da bacia não apresentar áreas de erosão linear significativas, as poucas existentes estão situadas sobre Argissolos, que apresentam um horizonte A que varia de 40 a $60 \mathrm{~cm}$ e logo abaixo um horizonte Bt que dificulta a infiltração da água que se acumula no horizonte A promovendo processos erosivos lineares nas formas de sulcos e ravinas. O quadro a seguir mostra a área ocupada pelas classes de solos na bacia.

Quadro II. Classes de solos e área ocupada.
\begin{tabular}{|c|c|c|c|}
\hline Classe de solo & Área $\left.\mathbf{( k m}^{\mathbf{2}}\right)$ & Área $(\mathbf{h a})$ & Área $\mathbf{( \% )}$ \\
\hline Latossolos & 83.4 & 8.340 & 60.8 \\
\hline Argissolos & 41.58 & 4.158 & 30.35 \\
\hline Cambissolos & 8.2 & 820 & 5.98 \\
\hline Neossolos litólicos & 3.27 & 327 & 2.38 \\
\hline Outros & 0.55 & $\mathbf{5 5}$ & 0.49 \\
\hline TOTAIS & $\mathbf{1 3 7}$ & $\mathbf{1 3 . 7 0 0}$ & $\mathbf{1 0 0}$ \\
\hline
\end{tabular}

Os Latossolos presentes na bacia variam conforme a litologia onde os mesmos foram formados, portanto são solos autóctones.

Aqueles desenvolvidos sobre rochas alcalinas (Gabros e Piroxenitos) que compõem as amostras de 1 a 3 apresentam coloração escura (Vermelho muito-escuro) segundo carta de cores de Munsell devido a alta presença de minerais ferro-magnesianos na composição mineralógica destas rochas. A textura é argilosa a muito argilosa.

Os Latossolos Vermelho-Escuros estão associados a rochas sedimentares das formações Furnas e Ponta Grosa e a textura varia de argilosa a Franco argila/arenosa.

Latossolos Vermelho-Amarelos estão associados às formações graníticas/gnáissicas, com solos de textura Franco/arenosa a Franco argilo/arenosa.

Os Latossolos Brunos aparecem tanto em áreas onde predominam rochas como os sienitos e 
XVII Simpósio Brasileiro

de Geografia Fisica Aplicada

I Congresso Nacional

de Geografia Física

\section{OS DESAFIOS DA GEOGRAFIA FÍSICA NA FRONTEIRA DO CONHECIMENTO \\ Instituto de Geociências - Unicamp \\ Campinas - SP \\ 28 de Junho à 02 de Julho de 2017}

granodioritos, como em rochas de coberturas sedimentares cenozoicas, e a textura varia de Franco arenosa a Franco argilo/arenosa. O mapa mostra a distribuição das classes de solos na bacia.

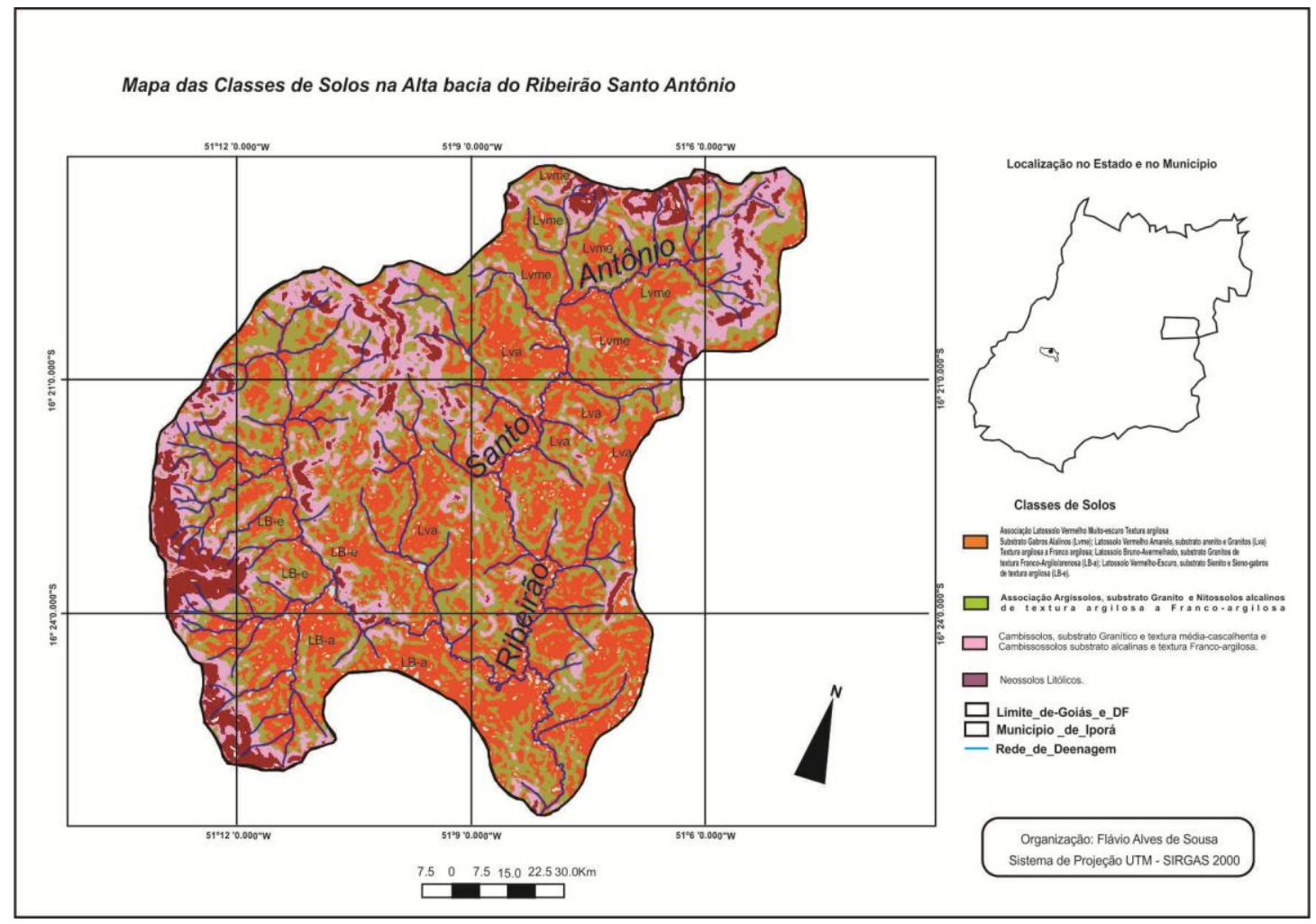

Figura 4. Mapa de Classes de Solos

\section{Condutividade hidráulica dos Latossolos.}

É possível notar que apesar da bacia apresentar mais de 60 de sua área formada por terrenos planos e predomínio dos Latossolos, os mesmos não apresentam boas condutividades hidráulicas, como é possível ver no quadro a seguir, onde $56 \%$ dos solos amostrados apresentam condutividades baixas e $31,25 \%$ condutividades muito baixas, e apenas $12,5 \%$ apresentam condutividade média.

A presença de pastagens nas áreas amostradas pode ser responsável por este fenômeno, que resulta em solos compactados superficialmente pelo pisoteio do gado e principalmente pela baixa taxa de conservação das pastagens, que em boa parte da bacia estão degradados. Outro fator é o gradiente textural, que quanto mais argiloso menor a condutividade, como se vê no quadro abaixo. Menor infiltração implica em maior erosão laminar que por sua vez implica em perdas de solos e em assoreamento de manancias.

Quadro III. A condutividade hidráulica dos Latossolos na Alta Bacia do Ribeirão Santo Antônio.

\begin{tabular}{|c|c|c|c|}
\hline Valores de referência & Pontos & Kv médio em cm/s dos & Textura
\end{tabular}




\begin{tabular}{|c|c|c|c|}
\hline $\begin{array}{l}\text { XVII Simpósio Brasileir } \\
\text { de Geografia Fisica Aplicac } \\
\text { I Congresso Naciona } \\
\text { de Geografia Físic }\end{array}$ & \multicolumn{3}{|c|}{$\begin{array}{l}\text { OS DESAFIOS DA GEOGRAFIA FÍSICA NA FRONTEIRA DO CONHECIMENTO } \\
\text { Instituto de Geociências - Unicamp } \\
\text { Campinas - SP } \\
28 \text { de Junho à } 02 \text { de Julho de } 2017\end{array}$} \\
\hline $\begin{array}{c}\text { em cm/s conforme } \\
\text { Terzagui e Peck (1967) }\end{array}$ & & solos amostrados & \\
\hline Médio: $10^{-1}$ a $10^{-3}$ & 9 e 10 & $1,52 \times 10^{-3}$ & $\begin{array}{l}\text { Argila arenosa e } \\
\text { Franco arenoso }\end{array}$ \\
\hline Baixo: $10^{-3}$ a $10^{-5}$ & $1,4,5,6,7,8,11,12,14$ & $3,96 \times 10^{-4}$ & $\begin{array}{c}\text { Franco } \\
\text { argiloso/arenoso a } \\
\text { argilosa }\end{array}$ \\
\hline Muito Baixo: $10^{-5}$ a $10^{-7}$ & $2,3,13,15,16$ & $3,34 \times 10^{-6}$ & $\begin{array}{l}\text { Franco argila } \\
\text { arenosa a muito } \\
\text { Argiloso } \\
\end{array}$ \\
\hline
\end{tabular}

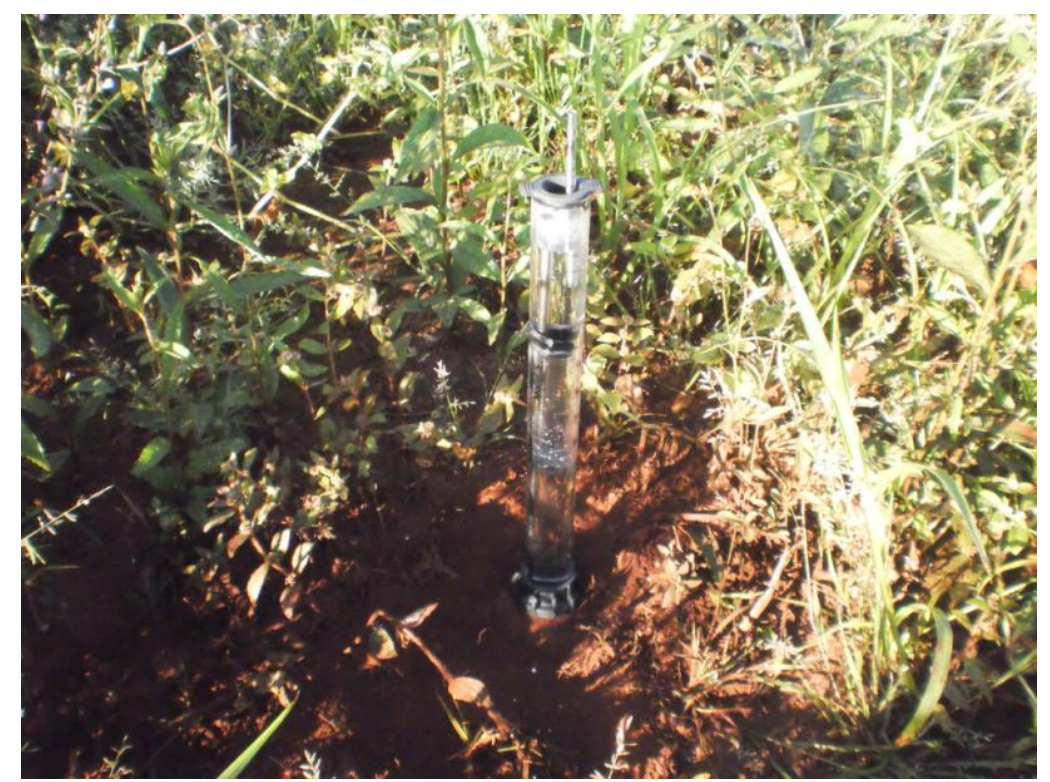

Figura 5. Infiltrômetro Mini-Disck utilizado na realização dos testes de condutividade hidráulica.

\section{Uso e ocupação da terra}

Sobre o uso e ocupação das terras a bacia apresenta um uso predominante por pastagens o que é justificado pela descontinuidade dos terrenos planos, que apesar de assentar uma maior parte de latossolos, não são suficientemente contínuos para o desenvolvimento da agricultura extensiva, como se pode verificar no mapa de uso a seguir, e no tamanho das áreas ocupadas por lavouras.

O uso por pastagens é então preferido pelos produtores, que inclusive ocupam áreas de declividades mais acentuadas, onde predominam o cambissolos, e há ainda a falta de preocupação com a fertilidade dos solos por parte dos mesmos.

As áreas de matas parcialmente preservadas estão circunscritas à pequenas manchas distribuídas aleatoriamente pela bacia, sendo que a maior parte delas está sobre terrenos mais íngremes constituídos por Cambissolos e Neossolos litólicos em áreas de divisores, onde o desmatamento é mais difícil e os solos são mais rasos. 
XVII Simpósio Brasileiro

de Geografia Fisica Aplicada

I Congresso Nacional

de Geografia Física

\section{OS DESAFIOS DA GEOGRAFIA FÍSICA NA FRONTEIRA DO CONHECIMENTO \\ Instituto de Geociências - Unicamp \\ Campinas - SP \\ 28 de Junho à 02 de Julho de 2017}

As matas ciliares estão relativamente protegidas ao longo dos mananciais sem, contudo, atender as larguras necessárias na maior parte da extensão dos cursos d'água. O mapa mostra a distribuição dos principais usos da terra na bacia.

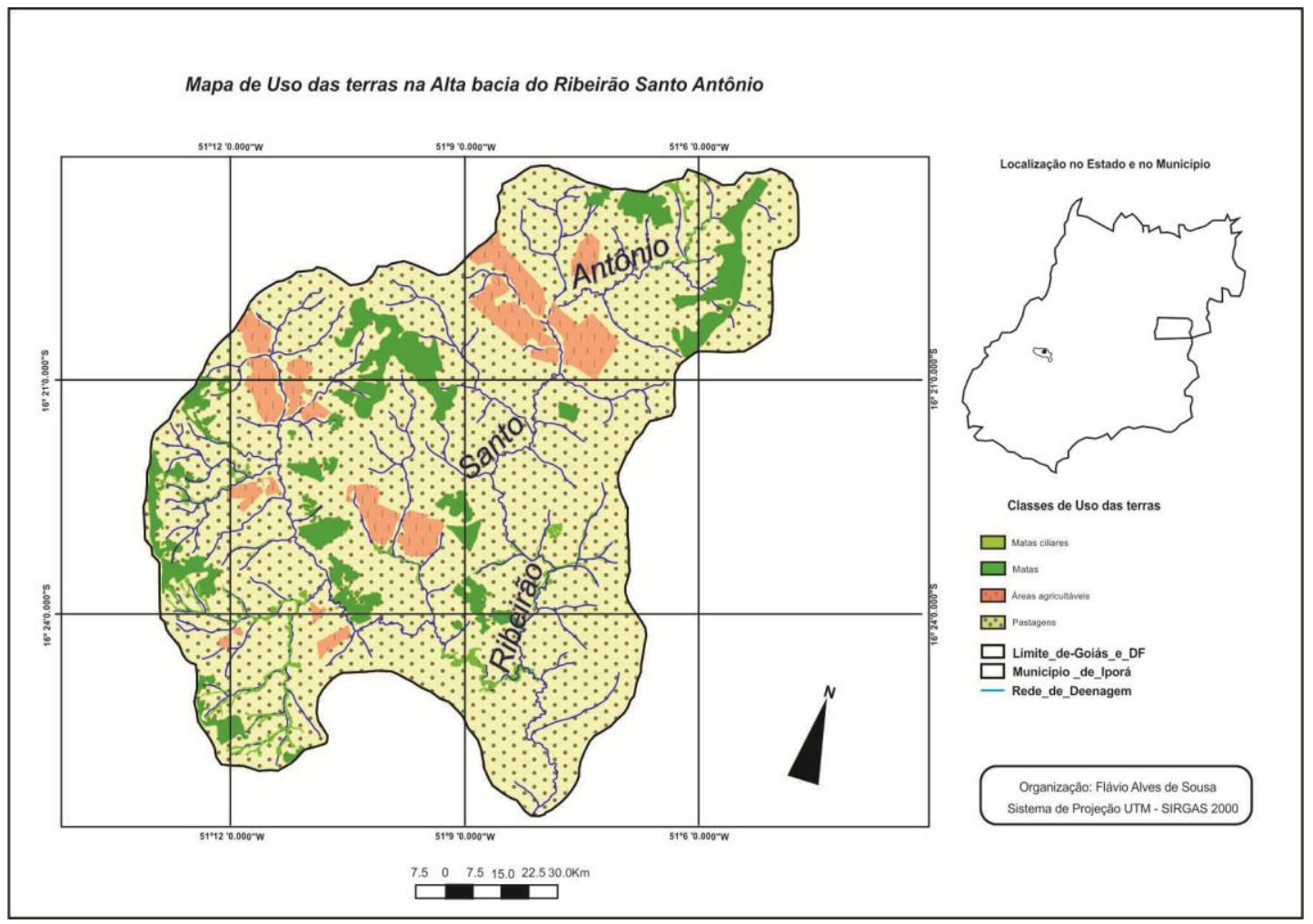

Figura 6. Mapa de uso da terra.

A seguir têm-se as áreas ocupadas por cada classe de uso.

Quadro IV. Áreas ocupadas pelos diferentes tipos de uso da terra.

\begin{tabular}{|c|c|c|}
\hline Classe de uso da terra & Área em hectare & Área em \% \\
\hline Agricultura & 952,9 & 6,69 \\
\hline Pastagens & $11.346,3$ & 82,82 \\
\hline Matas e Matas ciliares & $1.400,8$ & 10,49 \\
\hline Totais & $\mathbf{1 3 . 7 0 0}$ & $\mathbf{1 0 0}$ \\
\hline
\end{tabular}

\section{Considerações finais}

A partir do que foi avaliado, pode-se dizer que a bacia apresenta conservação de água e solos moderada, nem tanto pela iniciativa de planejamento, seja por parte do poder público, seja por parte dos proprietários de terras, mas pela própria condição natural da bacia, ou seja.

A bacia apresenta relevo suave ondulado a ondulado, que favorece uma relativa conservação da vegetação nativa nas áreas de encostas mais íngremes onde está a maior parte das nascentes.

Outro aspecto é a própria litologia, que associada ao tipo climático com dois períodos distintos, um 


\section{OS DESAFIOS DA GEOGRAFIA FÍSICA NA FRONTEIRA DO CONHECIMENTO \\ Instituto de Geociências - Unicamp \\ Campinas - SP \\ 28 de Junho à 02 de Julho de 2017}

chuvoso e outro mais seco, não favoreceu o desenvolvimento de terrenos planos, uma vez que a maior parte da litologia da bacia é formada por granitos e gnaisses, que são rochas resistentes ao intemperismo, e a sua modelagem resulta em relevo geralmente de topos convexos.

A condição geológica e climática inibe também as erosões lineares, que são muito inexpressivas na bacia.

Mas há problemas, que devem ser pensados e trabalhados em ações de planejamento para a conservação de água e solos, como por exemplo, nas áreas mais planas os solos estão superficialmente compactados, dificultando a infiltração da água, ou mesmo apresentam características texturais que também inibem este processo, e isso gera maior erosão laminar que atingem diretamente os mananciais, que estão cada vez mais assoreados, além de inibir a percolação da água em direção ao lençol freático, que em tempos de escassez de chuvas, alimentam os cursos d'água.

O uso das terras é predominantemente por pastagem, que na maior parte da bacia está em má condição de conservação, com solos compactados e sem técnicas de contenção da erosão, como as curvas de nível. As matas ciliares são mais extensas nos poucos locais onde predomina hidromorfia, pois nestes pontos o uso é mais dificultado, mas na maior parte dos cursos de água as matas são descontínuas longitudinalmente e estreitas. Quanto às matas (capões) estas aparecem integrais na imagem de satélite, todavia no campo sua base é ocupada por pastagens na maior parte dos casos. Cabe ainda destacar, que somando-se matas e matas ciliares a porcentagem é bem inferior ao exigido pela legislação ambiental.

Enfim, é necessário um planejamento no setor de microbacia para auxiliar na conservação da água e do solo na bacia, caso contrário com o aumento da demanda por água e com a má conservação da bacia, a mesma irá ser insuficiente para o abastecimento da cidade.

\section{Agradecimentos}

Agradecemos à Fundação de Amparo à Pesquisa do Estado de Goiás -FAPEG, pelo apoio financeiro através do programa de Participação em Eventos.

\section{Referências}

BERTONI, J. \& LOMBARDI Neto, F. - Conservação do Solo. Piracicaba/SP: Livroceres, 1985.

BIGARELlA, J. J. - A Serra do mar e a porção oriental do estado do Paraná. Um problema de segurança ambiental e nacional. Curitiba: Secretaria de Planejamento do Paranál associação de Defesa e educação Ambiental: 248 p. 1978.

CHORLEY, R. J. - A geomorfologia e a teoria dos sistemas gerais. In: Notícia geomorfológica. Campinas 11(21): 3-22, jun., 1971. 
GUERRA, J. T. \& CUNHA, S. B. da. - Degradação Ambiental. In: Geomorfologia e Meio Ambiente. Rio de janeiro: Bertrand Brasil, 2003.

GEE, G.W. \& BAUDER, J.W. Particle-size analysis. In: Methods of soil analysis. Part 1, 2nd ed., Madison, American society of Agronomy, 1986. pp 383-411.

ROSS, J. L. S. - Geomorfologia: Ambiente e Planejamento. São Paulo: Contexto, 1990.

SILVA, J. A . da. e BARROS, M. V. F. - Uso do solo no manejo de bacias hidrográficas: o caso da bacia do ribeirão Cafezal - Londrina Paraná. In: Geografia, meio ambiente e desenvolvimento. Márcia Siqueira de Carvalho (org.). Londrina: UEL, 2003.

SOUSA, F. A. de. Uso e ocupação na bacia hidrográfica do ribeirão Santo Antônio em Iporá-GO, como subsídio ao planejamento (Dissertação de Mestrado). Goiânia: IESA/UFG, 2006.

SOUSA, R. V. Barbosa \& CELEGOI, André. Avaliação da condutividade hidráulica do solo em área agrícola e florestada na cidade de Londrina (PR) com uso de permeâmetro de Guelph. Bol. Geografia. V. 29, n.2. Maringá, 2011. P. 123-133.

TRICART, J. - Ecodinâmica. IBGE/SUPREN. Rio de Janeiro, 1977,

VALENTE, O. P. - Manejo de bacias hidrográficas. In: SANEAMENTO Rio de Janeiro: 50(2): p. 104 - 109 , abr./jun. 1976. 